\title{
The 4S Web-Marketing Mix model
}

\author{
Efthymios Constantinides
}

\author{
Department of Technology and Management, University of Twente, Enschede, The Netherlands
}

Accepted 10 April 2002

\begin{abstract}
This paper reviews the criticism on the 4Ps Marketing Mix framework, the most popular tool of traditional marketing management, and categorizes the main objections of using the model as the foundation of physical marketing. It argues that applying the traditional approach, based on the 4Ps paradigm, is also a poor choice in the case of virtual marketing and identifies two main limitations of the framework in online environments: the drastically diminished role of the Ps and the lack of any strategic elements in the model. Next to identifying the critical factors of the Web marketing, the paper argues that the basis for successful E-Commerce is the full integration of the virtual activities into the company's physical strategy, marketing plan and organisational processes. The four S elements of the Web-Marketing Mix framework present a sound and functional conceptual basis for designing, developing and commercialising Business-to-Consumer online projects. The model was originally developed for educational purposes and has been tested and refined by means of field projects; two of them are presented as case studies in the paper.
\end{abstract}

(C) 2002 Elsevier Science B.V. All rights reserved.

Keywords: E-Commerce strategy; E-Commerce marketing; Web Marketing Mix; 4S model

\section{E-Commerce landscape in transition}

A recent report [1] predicts a Web population of over the 1 bln users in 2005, while many indications point to an upcoming fast growth of E-Commerce revenues and a growing consumer willingness to engage in online transactions $[2,3]$.

For the 210 Internet companies (a large percentage of them publicly traded) that shut their virtual doors in the year 2000 and the one dot.com that daily goes out of business since the beginning of 2001 [4,5] this kind of news sound a bit beside the point. In the Internet after-the-gold-rush period many of the first

E-mail address: e.constantinides@sms.utwente.nl (E. Constantinides). wave Web gold seekers struggle for survival by downsizing, streamlining processes and cutting costs, while academics, consultants, analysts, managers and journalists try to figure out what went wrong and ascertain the lessons to be learned from the present Web dejection. Learning is particularly important for the survivals of the crisis and the incumbents, who will be the next to join the virtual marketplace [6].

Analysing the causes of the Internet crisis Christensen [7] argues that the major factors for E-Commerce failures are the lack of awareness by many of the Internet players as to the basis of their industry competition and the failure of several businesses to exploit new technologies in a sustainable manner [8]. Lack of strategy and clear objectives [9], old-fashion product orientation, limited understanding of cus- 
tomer needs and poor commercial competencies are also frequently mentioned as issues having contributed to the continuing dot.com demise. An important, though less visible and often overlooked source of problems for the Internet players is the weakness of the traditional marketing paradigm, embodied in the well-known Marketing Mix framework proposed by Borden [10] and popularised as the 4Ps (Product, Price, Place, Promotion) by McCarthy [11], to provide an adequate platform for E-Commerce marketing management. The assumption that the 4Ps framework is widely used by E-Marketers as the underpinning of their marketing planning is based on the high degree of acceptance of the Marketing Mix by marketing practitioners as the universal marketing paradigm. Grönroos [12, p. 323] argues that the 4Ps framework has won an overwhelming acceptance among marketing practitioners, noticing that "... Marketing in practice has, to a large extent, been turned into managing this toolbox...", a point shared by Goldsmith [13, p. 178] who argues that the "...time-honoured concept of the 4Ps-the Marketing Mix ..." is the heart of the contemporary marketing management.

The shortcomings of the 4Ps marketing mix framework, as the pillar of the traditional marketing management have frequently become the target of intense criticism. Despite the fact that hardly any marketing textbook avoids mentioning the 4Ps, more than $75 \%$ of marketing academics are not satisfied with it as a pedagogic tool [14, p. 9]. The 4Ps framework is also criticised by researchers who identify several deficiencies in dealing with the marketing realities of today. A number of critics even go as far as rejecting the 4Ps altogether, proposing alternative frameworks. Ohma [15] reviews the 4Ps from the Strategic Management perspective concluding that no strategic elements are to be found in the model. He proposes that three Cs shape the marketing strategy: Customers, Competitors and Corporation. Bennet [16] suggests that the 4Ps are focused on internal variables and therefore form an incomplete basis for marketing. He suggests five Vs (Value, Viability, Variety, Volume and Virtue) as the criteria of customer disposition, while Lauterborn [17] finds the model too product oriented arguing that the customer must be placed in the centre of the marketing planning. One of the most outspoken critics of the 4Ps from the Relationship Marketing angle is Grönroos [12] who is identifying several reasons against using the 4Ps as a planning tool for marketing. He argues that the model has become a management straightjacket victimising not only the marketing theory but also the customer. Godin [18] considers also the Marketing Mix as an obsolete product of the mass marketing, unable to promote the personalisation required by modern marketing.

\section{The need for new E-commerce conceptual frameworks}

Essential differences between the virtual and physical commerce have prompted calls for a reevaluation of the existing marketing principles, when dealing with E-Commerce. According to Hoffman and Novak [19] "... marketers should focus on playing an active role in the construction of new organic paradigms for facilitating commerce in the emerging electronic society underlying the Web, rather than infiltrating the existing primitive mechanical structures". Such suggestions, added to the objections raised on the role of the Marketing Mix as the basis of the physical Marketing Management, have prompted several academics and practitioners to question the potential role of the $4 \mathrm{P}$ model for the virtual Marketing. These questions are frequently debated in E-Commerce forums and in a growing number of marketing management textbooks, academic papers and press articles. Two main streams are visible in this literature:

(a) Most writers addressing primarily practitioners' audiences, are usually focussed on outlining and optimising the management processes by identifying best E-Commerce practices [20-25] or advising on Web design tips [26]. A basically descriptive and process-focused methodology is followed by Chaffey et al. [27] outlining the E-Commerce marketing planning as a process based on eight decision points. Seybold [28] had earlier proposed a similar approach while Oliver [29] identifies seven E-Commerce laws as the basic parameters of the E-Commerce strategy. 
(b) Contributions of academics and practitioners focused on E-Commerce marketing have yielded a growing list of articles and books. Some writers focus their attention on value creation [30,31] while others distillate on the differences and similarities between traditional commercial practices and Web business models [32] or processes [33]. Angehrn [34] proposes a strategic model of a merely descriptive and explanatory nature, suitable for diagnosing the maturity and strategies of E-Commerce sectors as well as structuring and detecting opportunities in individual companies. Another modelling approach is suggested by Huizingh [35] who delimits the online commerce issues by the Strategic Internet Applications Model (SIAM), the Customer Interaction Cycle (CIC) and the Accessibility, Design, Offer and Fulfilment (ADOF) model. Lawrence et al. [36, p. 79] propose the Marketing Mix as a proper basis of E-Commerce marketing activities.

Despite the growing attention on strategic modelling there are still, according to Chaffey et al. [27, p. 152], " ... a few appraisals of methods of implementing an Internet marketing plan from an academic viewpoint". Writers attempting to develop such a viewpoint often choose for a conservative approach by resorting on established Marketing Management concepts and suggesting ways to convert existing frameworks into usable concepts for the online Marketing. This approach often emphasises the role of the Marketing Mix 4Ps model as the proper basis of the Marketing Management planning in virtual environments. A number of writers suggest that the 4P model could constitute the conceptual platform for E-Commerce marketing planning virtually unchanged [36,37]. Others suggest a few transformations in order to adapt the model to the digital marketplace [38], while O'Connor and Galvin [39] are diagnosing Marketing in a condition of a mid-life crisis and argue that new technologies can improve and optimise the 4Ps-based management process. The obvious explanation for the loyalty of many writers to the 4Ps model is its undisputed record, intrinsic simplicity and comprehensiveness, making it a very popular tool among practising marketers as explained earlier.

\section{The traditional Marketing Mix paradigm is incompatible with E-Commerce}

The Internet, as commercial environment, embraces some of the most substantial developments that took place in the marketing landscape of the last 40 years. The virtual marketplace epitomises the evolution process from the mass markets of the 1960 s to the increasingly segmented, niche-dominated or even mass-customised, highly interactive and global markets of today. The effect of the new setting is that the focus of marketers has shifted towards satisfying individual and personalised rather than collective needs while placing much more emphasis on customer retention, customer service and relationship marketing. Such changes follow closely the shifting behaviour patterns of new generations of individualistic, better informed, wired and wealthier consumers. Consumers increasingly demanding more control over the marketing process [40], value the personalised approach and prefer products or services that can be promptly adapted to their constantly changing needs.

Having analysed the criticism on the role of the Marketing Mix as the marketing paradigm in the physical world one could argue that this criticism is reconfirmed when attempting to apply the 4Ps in the virtual environment. One obvious weakness is the fact that the model does not explicitly include any interactive elements $[12$, p. 324], while interactivity is the basis of the Internet Marketing. It can be argued furthermore that two more important points are indicating the limitations of the 4Ps in the virtual marketing.

(1) Applying the Marketing Mix model in traditional markets implies that the four $\mathrm{P}$ parameters of the model delimit four distinct, well-defined and independent management processes. Despite the consistent effort by many physical businesses to deal with the 4Ps in an integrated manner, the drafting but mainly the implementation of the $\mathrm{P}$ policies remains largely the task of various departments and persons within the organisation. Even more significant though is the fact that the physical customer is typically experiencing the individual effects of each of the 4Ps in diverse occasions, times and places, even in cases that companies take great pains to fully integrate their marketing activities internally. 
Unlike the physical world, in the virtual marketplace the four elements of the mix are not detached from each other. They are heavily interrelated and for all intents and purposes jointly experienced by the online customer, being merely parts of the content of the CompanyCustomer interface, better known as the Web Site.

This suggestion has important implications for the customer's buying behaviour. While the traditional buyer behaviour model [41, p. 161] considers the 4Ps as the controllable factors likely to influence the conventional consumer's buying decisions, it is the Web Experience- the Web experience is the consumer's impression about the online company [42] the factor under the marketer's direct control likely to influence the buying behaviour of the online consumer. From the customer's perspective the Web site depicts the very aspects likely to prompt his reaction to the online offering, the 4Ps being merely a part of the site based Web Experience and as such simultaneously experienced by the customer [48].

\subsection{Product}

The Web site is the prime online product and brand of the online organisation. The customer should become aware, develop interest and be persuaded to search for the site/product before going on looking into the company's detailed online offering.

\subsection{Price}

The majority of commercial sites function as price lists for the company's physical product assortment. Besides that, the Web site is perceived by the online prospect and customer as a cost element (due to connectivity cost,transaction costs, time and opportunity cost). Although this costs will be in most cases lower than the cost of performing these activities physically, the customer will compare these with the cost of finding other online competitors and doing business with them.

\subsection{Promotion}

The Web site is the promotional medium as well as the promotional content. The communicational and emotional impact of the Web site is an important part of the Web experience and a major factor in attracting and retaining online customers.

\subsection{Place}

For the majority of E-Commerce cases involving any form of online interaction-transaction, the Web site is the counter, helpdesk and sales outlet where the actual commercial or non-commercial transaction takes place. Moreover for products delivered in digital form (music, information, software and online services) the site fulfills even the task of the physical distributor by allowing the product delivery online.

The above analysis suggests that attempting to approach the 4Ps in isolation in the Web environment is not a sound strategy, since online customers by and large experience them in a simultaneous and direct manner, as elements of the Web site-based customer experience. For Internet customers this experience will include many other elements like findability of the site, ease of navigation, prompt replies to e-mails and easy to use shopping and payment procedures and will be the criterion for the customer to come back to the site or not.

(2) The 4Ps Marketing Mix paradigm has been developed as an operational rather than a strategic tool and conventional marketers have always treated it as such. In the physical world the strategic management aspects are in effect separated from the commercial operations due to the very nature of the strategic management itself. Most marketers regard therefore the corporate strategy as an external variable over-imposed to their marketing mix. Applying the 4Ps Marketing Mix model as the sole planning platform for E-Commerce operations could mean that the strategic aspects would remain underexposed or disregarded altogether. An option for defining the strategy of an online organisation is to follow the conventional strategic management procedure [43,44] but two hitches make such an option often unattractive for Web marketers:

- The conventional strategic process is by nature time consuming and time in the Web is often in short supply.

- The volatile, fast changing and constantly evolving nature of the Internet can rapidly 
outdate conventionally developed strategies making them abruptly obsolete [29].

The customary strategic management processes is in other words time consuming, inflexible and in effect inappropriate for the dynamic and unpredictable online markets. The shortcomings of the classic strategic approach can explain the obvious aversion for strategic planning by the majority of dot.coms [45]. Most brick-and-mortars entering the Web on the other hand would presumably find it more convenient to apply their existing strategic model to their Web operations rather than delineating a new E-Commerce strategy. In some cases such a policy is sensible, in other cases not. British Airways (BA) learned the hard way that competing online on the basis of the existing strategic model with EasyJet.com and other value-oriented airlines was impossible. After the initial poor results of the new BA Web site as a ticket counter the company drafted a new strategic approach by launching the low-cost offshoot airline Go to compete in the online lowbudget market.

A way of solving the Web strategy problem is by integrating the online strategic planning into the operational marketing planning, this way building much more flexibility into the system. This would mean introducing an E-Commerce 'micro-strategy' that while in line with the corporate physical strategy would be flexible and easily adaptable to fast changing online conditions.

\section{The Web-Marketing Mix (WMM) model}

The Web-Marketing Mix model identifies the online marketing critical elements and addresses the main E-Commerce strategic, operational and organisational issues in an integrated and manageable manner. The WMM is an appropriate basis for the Web Strategic and Marketing planning, especially intended for click-and-mortars operating in the in the Business-to-Consumer segment. The tool is designed primarily for conventional, physical corporations planning to establish an Internet presence. The model can be also useful to pure-plays or existing online organisations in re-evaluating their E-Commerce presence, provided that such organisations already have or are considering having a physical presence next to the virtual one.

The Web Marketing Mix approaches the marketing planning process in an integral manner, on different levels:

On strategic level the model identifies the main strategic issues to be addressed in order to build up a flexible, value adding and potentially successful ECommerce organisation. The model emphasises the fact that online activities should be assigned their own strategic objectives in line with the corporate ones. Next to that it recommends the highest possible assimilation of the online venture into the physical corporate commercial strategy in order to capitalise on the existing organisation's strengths and competitive advantages.

On operational level the WMM proposes a method for drafting realistic and consistent Web marketing plans. The prime objective of the operational planning is the development of a market-oriented, effective, flexible and unique online presence.

On organisational level the WMM addresses the issue of building up the proper organisational, human and knowledge infrastructure necessary for a smooth online operation. The model identifies areas where a high degree of integration of the virtual business into the corporate infrastructure is necessary in order to maximise the synergies between the virtual and physical business and improve the overall organisational efficiency.

Next to these three main focus areas the WMM denotes the need for further improving the competitiveness of the online organisation by seeking synergies with 'complementors' i.e., third parties or industries. These complementary firms have been recommended by Shapiro and Varian [46] as the sixth force to be added to Porter's five competitive forces model in order to fully understand the competitive strength and competitive position of firms operating in information markets.

Finally the model identifies the main technological and administrative issues that will underpin E-Commerce activities.

The above-mentioned issues describe the successive steps of the Web commercial planning methodology and are classified in four groups. Each group is labelled by a word beginning with the letter S namely the Scope, Site, Synergy and System 
(Exhibit 1). The content of each S-group is based on the previous steps but feedback during the planning process is necessary for fine-tuning of each step. The final result - the Web Strategic and Marketing Planwill become the basis of the Internet project, the groundwork of a process including several more stages: the development of the technical and organisational infrastructure, the technical implementation, the testing of processes and the commercialisation of the Web site.

Finally, it should be mentioned that the fast changing character of the Web makes it imperative that the planing procedure is frequently repeatedthe frequency depending on the branch, the market developments and the competitive reactions-in order to maintain the competitive advantage of the online organisation overtime.

\section{Description of the Web-Marketing Mix model}

The Web-Marketing Mix identifies four online marketing strategic, operational, organisational and technical critical factors: the Scope (strategic issues), the Site (operational issues), the Synergy (integration into the physical processes) and the System (technical issues) (Table 1).

\subsection{Scope}

This content of this element is of primarily strategic character and outlines the decisions to be made on four areas:

(a) the strategic and operational objectives of the online venture;

(b) the market definition including measuring the market potential and the identification/classification of the potential competitors, visitors and customers of the site;

(c) the degree of readiness of the organisation for E-Commerce;

(d) the strategic role of E-Commerce for the organisation.

More specifically:

\subsubsection{Objectives}

The online activities must pursue their own, clearly defined strategic objectives, in line with the corporate mission and strategic goals. This way the online operation will be able to generate additional value and assist the physical organisation to attain the corporate objectives.

Online strategic objectives do not essentially differ from the traditional ones and are subject to the same quality criteria. Such objectives can be: enhancing profitability, improving the company image, raising revenue, reducing operational costs, expanding the customer base, increasing the customer retention or augmenting the product and brand awareness among new groups. The Web objectives will form the basis for outlining the operational trajectory of the ECommerce venture, based on different tactics or combinations of tactics. Increasing revenues, for example, could be realised by online promoting the company brands and company products and expanding the brand awareness while at the same time launching promotional activities in order to attract new and existing customers to the physical sales outlets. The same objective could also be reached by a retention-oriented site aiming at improving customer service and customer relations or even by establishing an online sales outlet.

\subsubsection{Market analysis}

It is of vital importance for Web companies to identify their market domain, market potential, the profiles of potential customers and the online strategies of competitors. The global character of the Internet, the fast growth of online businesses and users' numbers, the changing demographics of the online population and the limited familiarity of many mainstream managers with E-Commerce makes the market analysis a challenging task. The analysis, however, will yield a clear picture as to the market size, customer profiles, competitive situation and future trends. It will also reveal new market opportunities, assist the budgeting process and provide creative ideas as basis for the online marketing activities.

Identifying the potential online customer and his or her needs is the task often posing most difficulties. This due to the fact that the potential online buyer can be quite a different individual from the physical 
Table 1

The Web-Marketing Mix

The 4 Ss of the Web-Marketing Mix

\section{Scope: Strategy and Objectives}

Market Analysis: Competition basis, competitors, market potential, market forecast, market trends

Potential Customers: Profiles, motivation, behaviour, needs and current way of fulfilling them, priorities

Internal Analysis: Internal resources, processes, values. Is the Web a sustaining or disruptive technology?

Strategic Role of the Web Activities: Generic types: Informational, Educational, Relational, Promotional, Transactional

\section{Site: Web Experience}

Customer oriented content. Important questions:

- What does the customer expect in the site?

Domain name, content, design, layout, atmosphere, aesthetics and web site positioning and the classic 4 Ps

\section{- Why the customer will make use of the site?}

Simplicity, functionality, speed, findability, searchability, navigation, interactivity and customisation

-What motivates customers to come back?

\section{Synergy: Integration}

Front Office integration: Integration with the physical Marketing Strategy and Marketing Activities

Back Office integration: Integration of the Web site with Organisational processes, Legacy systems and Databases

Third Party integration: Create networks of partners who will assist the commercial, logistic and other site activities

\section{System: Technology, Technical Requirements and} Web Site Administration

Software, hardware, communication protocols, content management, system service, site administration, hosting decisions, payment systems, performance analysis 
customer who traditionally buys the company's products and services. Web clients can be persons with different buying motives, cultural backgrounds, needs, demographic, technographic or lifestyle profiles from the conventional customers. Moreover, online clients can be located outside the geographical areas where the company normally operates, a fact by itself raising serious logistic, legal and administrative problems.

In case that market research data is not available, a number of initial, basic assumptions must be made as to the most likely profiles, needs, motives, attitudes and demographics of the potential Web customers. These assumptions will help the online marketer to identify potential market segments and decide the initial site positioning, unique selling proposition, style, design, structure, product assortment policies and pricing strategy. Assumptions made in this initial stage should be constantly refined using online as well as physically collected customer and market information.

\subsubsection{Internal analysis}

Adoption of new technologies can have sustaining or disruptive effects on organisations, depending on the firm's resources, processes and values [8]. The internal analysis should be focused on these three factors in order to identify the degree of company readiness to assimilate E-Commerce and assess the possible effects of it on the organisational value chain [47]. Based on the internal analysis the management will further refine the Web strategic objectives and will identify the proper Strategic Role (see Section 5.1.4) of the online activity. The management will obtain a clear insight into to the real costs of the operation not only in financial terms but also in terms of disruption of the established physical processes and infrastructures. It is likely that in some cases the outcome of the internal assessment will be a No-Go decision, due for example to the high degree of organisational disruption, low added value or extremely high expenditure against low expected benefits. In such cases the management should consider alternative options, one of the possible alternatives being separating the Web operations from the existing corporate body. While such a strategy seems often to be an attractive solution, such options must be always treated with caution [9].

\subsubsection{Strategic role}

The strategic role describes the tasks assigned to the online activity and will be reflected on the firm's online model.

Web marketers can choose between a number of generic strategic roles, the most common being the informational, educational, service oriented, promotional, relational and transactional ones. The actual strategic role-the business model-is frequently based on a combination of more of these generic types.

An example: the strategic role assigned to the Web presence of an insurance company can be an informational one (an online brochure), i.e., simply informing the site visitors about the company and assisting potential customers to find information about its products and dealer network. The role, however, will be a transactional one (an online insurance agent) if the company chooses to sell its products online.

The strategic role as defined here, will have important consequences for the site identity, positioning, style and atmosphere, content, structure, functionality, organisational/technical infrastructure and any other element of the Web Experience. The objective of the E-Marketer must be to differentiate the site and create a Web Unique Selling Proposition appealing to the target group(s), conveying customer value and consolidating competitive advantages. Such a proposition must be:

- proprietary, hard to be imitated by competitors;

- able to produce win-win situations with the existing business partners;

- flexible enough to be easily adapted to changing market conditions and external developments.

\subsection{Site}

The Web Site is the company-customer interface, the prime source of customer experience and therefore the most important communication element of E-Commerce.

As explained earlier, the Web site is the virtual product display, promotional material, price catalogue and sales/distribution point. The Web site is therefore the functional platform of communica- 
tion, interaction and transaction with the Web customer.

The prime mission of the Web Site is to attract traffic, establish contact with the online target markets and brand the online organisation. Next to this 'generic' mission the Web site can be assigned a mix of commercial objectives-but often also non-commercial ones like personnel recruitment, shareholders info, etc.- and tasks, depending on the previously defined strategic role. Some of the common site objectives and tasks are:

- communicating and promoting the E-business image, labels and products/services;

- providing company information to customers and stakeholders;

- effectively communicating the firm physical or virtual promotional activities;

- providing customer service and helpdesk functionality in order to enhance the customer loyalty and retention;

- providing sales leads and customer/market data;

- allowing customers to communicate and interact with the company as well as creating online content;

- allowing direct sales and facilitating online payments (transactional sites).

A number of Internet-specific aspects like domain names, site and transaction security as well as privacy policies are critical parameters of the Web site and the Web experience. Online privacy and protection of personal data are often overlooked by online businesses despite the fact that millions of consumers seem to be very concerned about the way their personal information is used. According to Forrester Research this lack of confidence represented as much as $\$ 12.4$ bln in lost sales in the year 2000 [45].

It is obvious that the Web site is expected to fulfill a variety of roles not common to any single conventional marketing instrument. Assigning roles to a Web site while maintaining its functionality and user friendliness is a delicate process depending not only on the available funds and technological options but foremost on good knowledge on the potential customer's motives, needs, expectations and behaviour.

Special attention must be finally placed to aspects like the site findability and site speed, keeping in mind the average user's skills, available bandwidth and other technical limitations.

\subsection{Synergy}

For the purpose of this analysis we define term Synergy as the integrating processes necessary for realising the virtual organisation's objectives. Such synergies can develop between the virtual and the physical organisation as well as between the virtual organisation and third parties.

The above definition implies that the following analysis is appropriate for organisations with both physical and virtual presence, i.e., brick-and-mortars engaging in E-Commerce or Internet companies willing to establish and develop some type of physical commercial and organisational presence next to the virtual one.

This Synergy factor embraces a wide range of issues divided into three categories: The Front Office, the Back Office and the Third Parties.

\subsubsection{The Front Office}

The Web industry usually refers to the front office as the web site itself. In the context of the WebMarketing Mix model the Front Office refers to the conventional corporate communication and distribution strategies. The Front Office element underlines the need to examine and identify ways that would facilitate the full integration of the Web operation into the company's communication plan, corporate style as well as the existing physical retail channels.

Incumbents intending to establish an online presence must analyse the extent, magnitude and financial cost of the adjustments necessary in order to accommodate and integrate the communication of the virtual activities into their current promotional plan. The effort must be focused on utilising existing communication strategies, brands, tools and channels in order to promote and support the Web operation during the introduction stage. The objective of this communication is to inform existing as well as potential customers about the future Web activities and outline the advantages of doing business online.

The need for integration and synergy between the online and the physical communication plan is obvious. Utilising existing promotional activities and 
capitalising on embedded customer goodwill is economical, less time consuming and more effective than launching new promotional campaigns with the purpose of establishing new commercial concepts and brand identities. Furthermore existing customers are more sensitive than non-customers are to company communication and most probably willing to make use of the online functionality.

The synergy of the online operation with the Front-Office activities will obviously not be limited to the introduction stage of the E-Commerce project. One should expect that in the long run in the majority of cases the dependence of the virtual business on the physical business will be gradually reduced while the dependence of the physical business on the web will most likely increase. A mature online operation will be able to support the corporate marketing strategy as a low-cost source of customer and market data as well as a retail outlet and an efficient communication instrument.

In addition to the promotional integration the web operation must be able to operate along the existing distribution framework adding value to it. Traditional distribution channels are often resisting on line sales fearful of profit cannibalisation. Empirical evidence, however, reveals examples of successful integration of virtual business with existing distribution channels without serious disruption of existing business [7]. A good example (but certainly not the only one) are mail-order or telephone sales firms who have been able to fully utilise existing logistics infrastructures since the similarities between their conventional and virtual business models are obvious [6]. The task of the Web marketer is to find ways to minimise the channel conflicts by recognising possible mutual benefits and translating them into win-win situations for all parties.

\subsubsection{The Back Office}

This Back Office synergy embraces a wide set of issues, including:

1. the integration of E-Commerce physical support activities (customer service, order processing, fulfilment and reverse logistics) into the existing organisational processes;

2. the legacy integration;
3. integration of the online operation into the company's value system [43].

Making existing organisational infrastructures available to the online operation is a more sensible option than crating new ones. Next to the obvious cost aspects, the online organisation is likely to benefit from economies of scale and learning effects. Whenever changes in existing infrastructures are necessary, in order to meet the usually higher quality standards of the Web operations, such changes will be beneficial for the organisation as a whole, physical and virtual. Therefore, E-Commerce can become a catalyst of organisational re-engineering and change. In more detail:

1. Organisational integration. Integration into the existing support operations is necessary for the online firm in order to be able to provide the fulfilment and Back Office support expected by Web customers. Back Office efficiency is essential from the very moment the Web operation goes live and customer data, queries and online orders begin streaming in. With competitors only one click away, customers disappointed or frustrated by poor fulfilment and service need to put very little effort to bring their business elsewhere.

Online service, the Achilles heel of many Internet businesses, is an extensive domain where a wide variety of problems and situations can occur. Poor Web service practices range from simple failure to react or overdue reaction to customer e-mails to more complex problems like frustrating ordering and return procedures, lack of order tracking, inefficient helpdesk support, poor after-sales service. Failure to meet delivery deadlines, non-delivered goods, incorrect or inferior quality products and erroneous invoicing are also common fulfilment flaws.

The Web manager should evaluate the physical Value Chain [9] and its capacity to facilitate the Web Back Office needs. Such an evaluation, utilising the previously conducted Scope analysis (see Section 5.3.3), will reveal possible weaknesses and outline the changes necessary in order to upgrade the existing Back Office to the necessary quality level. Constant monitor- 
ing-requiring efficient auditing mechanisms, benchmarking and close monitoring of customer behaviour-must detect flaws and initiate corrective action.

2. Legacy integration. Integration of online activities into the existing Information Infrastructure including Management Information Systems (MIS), Efficient Resource Planning (ERP) Systems, databases and data warehouses is vital for the management and administration of ECommerce activities. Efficient utilisation of the company IT legacy will result in cost advantages, improved decision-making and more efficient information management.

3. Integration with the company Value System. In cases of transactional sites the Back Office integration process should expand beyond the company boundaries and include all external participants in the firm value system: intermediaries, suppliers of raw materials and any other parties directly or indirectly affecting the production, distribution and logistic processes. Online ordering, typical for transactional sites, requires Efficient Consumer Response (ECR) strategies: synchronised production, JIT and efficient inventory management. Such tactics demand a high degree of efficiency within the Value System. Moreover Intranet and Extranet replacing expensive proprietary EDI and EFT systems as functional platforms will allow cost reductions and higher efficiency.

\subsubsection{Third parties}

Next to the synergies described above, success in the virtual marketplace often requires co-operation with Internet partners outside the organisation and its value system. This networking aim at strengthening the competitive position of virtual organisations and the network must be seen as complementary to the traditional promotional activities. Candidate partners for such online synergies are:

- Search engines and Web directories. These partnerships can increase the exposure of the online organisation into the Web marketplace by allowing online customers to locate and easily access the site. Learning the way search engines and Web directories operate and delineating search engine strategies can result in substantial increase of the Web site exposure, attracting a substantial percentage of Web users who use such tools when searching for online products, information and services. The search engine strategy is based on a combination of active registration and the effective use of techniques and programming tools (for example meta-tags) increasing the chances of the Web site to be listed in high positions in search queries. A sound search engine strategy provides finally for mechanisms allowing the frequent evaluation of the site findability and if necessary fast corrective action.

- Affiliate networks. Affiliate networking is a popular method of online promotion, introduced and popularised by amazon.com. On line organisations create affiliate networks by recruiting other sites willing to place a banner or a link on their pages in exchange for a commission based on click-through or more commonly on revenue generated by click-through customers.

Such networks can substantially strengthen the market exposure of online organisations in a cost-effective manner making them an attractive option to many new online organisations. Next to creating their own affiliate networks online organisations can become members of other affiliate schemes in order to generate additional incomes.

Management issues and the possible association of the online company with questionable partners participating in the network are the main points of concern around affiliate marketing.

- Online advertising. This type of promotion is based on placing interactive advertisements (banners, buttons or hyperlinks) at high traffic sites or sites likely to attract potential customers at a cost usually based on the popularity of the advertising site.

Industry observers have often questioned the effectiveness and value of online advertising as a promotional medium. This because clickthrough rates ${ }^{1}$ (ranging typically between 3 and

\footnotetext{
${ }^{1}$ Click-through rate is the percentage of the visitors of a Web Page
} clicking-through on an advertising banner or button. 
5\%) are perceived by many advertisers as low but the question whether the click-through rate is a sufficient basis for evaluating the effect of online advertisement in its totality, has not been fully answered yet.

The selection criteria of partners for online advertising are obviously more stringent that the criteria for appointing affiliate partners while efforts to relate fees to actual and measurable results will sooner or later become the subject of a wider industry debate.

Next to the careful selection of partners other success factors of online advertising are the originality, capturing power and timing of the advertising copy.

\subsubsection{System}

This factor identifies the technological issues as well as the site servicing issues to be addressed by the E-Commerce management. In the early days of the commercial Web, technology was widely considered as the main driving force behind the Internet growth. This fact often led to technology overkill, undermining the strategic and commercial principles that should underpin any online organisation. Technology overdoses can result in customer confusion, dissatisfaction, diminishing Web experience and lost business. Despite the fact that ICT remains the functional backbone of the E-Commerce, the role of technology must be put into perspective and technology should never become the starting point of online activities.

The main areas where the System-related decisions are to be made are:

- Web site administration, maintenance and service. Availability of technical and service personnel on a 24-h, 7-days a week basis is the basic requirement for a reliable site.

- Web server hosting and choice of the Internet Service Provider. External hosting is a popular option mainly for small and medium-size organisations.

- Site construction. Constructing an above the average, transactional E-Commerce site requires a substantial initial investment. Outsourcing this activity is usual, there are however many edit- ing tools available for low-budget solutions. Presentation quality, user friendliness, easy navigation, browser independence and speed are important success factors determining the choice of programming and development tools.

- Content management. Important elements of content management are the frequent reviewing and updating of the content in response to constantly changing customer needs, market conditions, competitive strategies and market trends as well as the decentralisation of the Web site updating procedures. The later requires training and empowerment of employees of different departments in managing the site data under their responsibility and is needed for avoiding bureaucratic procedures harmful for the content quality.

- Site security. Protection against any forms of malicious attacks as well as transaction and customer data safety are paramount concerns of E-Commerce managers and online customers alike. Identifying the proper security level for each content category is a sensitive issue since increasing security levels usually result in reduced functionality or diminishing user friendliness. A good approach is customising security levels on the different site elements therefore avoiding unnecessary safety overdoses while the sensitive data is adequately protected with minimum functionality sacrifice.

- Transaction functionality. The main elements here are the construction of communication interfaces, the choice of the transaction and payment technology, the testing and administration of the system.

- Collection, processing and dissemination of the Web site traffic and transaction data. These type of data fulfill, next to their administrative significance, an important commercial role as the vital input for evaluating the site performance, testing new ideas or assessing the effect of promotional activities.

- System backup. A sound back-up mechanism is vital for Internet organisations expected to be operational on an around-the-clock availability basis. Technical problems and system failures must be quickly addressed with the minimum operational disruption. 
Finally the site technical management must regularly and in collaboration with the commercial management identify and evaluate new technologies and new available products that could upgrade the site performance, enhance the customer experience and effectuate operational economies.

\section{Implementing the Web-Marketing Mix: two exploratory cases}

\subsection{The background of the case studies}

During the second half of 1998 making use of a sabbatical leave I accepted the invitation of a consulting firm in Athens, Greece, to work as E-Commerce consultant for a period of 6 months. This appointment was an excellent opportunity to test in the field the applicability and practical value of the $4 \mathrm{~S}$ model as the basis of E-Commerce strategic planning. The two cases presented are summarizing the main issues resolved during the planning process of the E-Commerce activities, based on the WebMarketing Mix model. The planning process produced a strategic and operational blueprint that became the basis of the whole E-Commerce project.

The case studies explain how the $4 \mathrm{~S}$ framework has been applied in the field and outline the main empirical conclusions drawn from these particular projects. The purpose of the case studies is assist the reader to understand how the methodology works rather than evaluate the actual commercial or other results of the online activities in question.

\subsection{Case 1: the ABC Portfolio* case}

\subsubsection{The Web presence of ABC Portfolio*}

ABC Portfolio* is a Portfolio Management firm based in Athens, Greece. The firm was at that time a new player in the Greek financial market and commenced operations in 1998. The company management decided to introduce a corporate web site that would be launched simultaneously with the first of the company's products, the ABC Mutual Fund*.

The 4S Web-Marketing Mix framework was used as the platform for drafting the Strategic and Marketing plan for the company online activities. This plan would provide the framework for developing and commercialising the corporate Web site and integrating the online with the traditional company operations.

Prior to the introduction of the first of $A B C$ Mutual Fund* products, the company launched a mass media advertising campaign. The objective of the campaign was to create brand and product awareness and to position the ABC Mutual Fund* as a new investment fund managed by a highly skillful and dynamic management team. Next to the management qualities other key words of this campaign were the terms Teamwork, Information, Openness and Reliability.

The basic problems to be addressed in designing and commercialising the corporate site were:

- how the Web presence can add value to the company and what role the site should play as a company strategic element;

- how the Web site could attract and retain visitors;

- how the Web operations would be evaluated.

Having defined these problem areas a detailed strategic and marketing plan was drafted based on the $4 \mathrm{~S}$ framework. Due to the limited time available, most of the required market and customer information was obtained by means of desk research and expert interviews.

The main elements of the plan based on the 4Ss were:

\subsubsection{Scope (strategy)}

Potential site visitors would be portfolio managers, shareholders, private investors and the press. The target market was primarily the Greek market but also English-speaking individuals. Considering the number and profiles of Internet users at that time in Greece the objective as to the average number of potential visitors of the site was estimated to be between 1000 and 5000 daily.

One of the main difficulties at the time was the limited Internet experience among the majority of the potential users at that time. Most potential users preferred the traditional sources of information and traditional ways of contact with investment funds. Turning to the Internet could be a difficult step if that involved complicated and time-consuming processes. 
The main motive for visiting the site was thought to be finding reliable and up to date market information and access to market analyses that would reduce investment risks taken by visitors: portfolio managers, investors and stockholders. Other type of information interesting to the potential visitor would be company news, and the actual price of the fund's stock closing price. Next to that site visitors should be able to find a daily update on the fund's net asset value and portfolio composition. The last two elements were a major innovation for the Greek market, considering that investment funds are obliged by law to publish this data on quarterly basis.

Major factors influencing the site visitor to use it and return to the site would be the high quality of the information found in the site as well as the speed, easy navigation and user friendliness.

The main strategic objectives of the ABC Web site were formulated as follows:

(a) To become the prime source of market information about the Athens Stock Exchange.

(b) To become a source of company value as a promotional and relational site. This should be achieved by assisting the overall marketing effort in communicating the company brand and products as well as attracting and retaining a number of site users that would become, on basis of their own consensus, the prime prospects for future company products.

\subsubsection{Site (operational aspects/web experience)}

Based on the above strategic analysis it was decided that the site experience should be based on the following elements:

- Information would be the 'strategic product' offered by the site. The Unique Selling Proposition of the site became the Power of Information, a position that would appeal to the target group. Openness, honesty and respect for the customer were also basic elements of the site positioning.

- The site design should allow ease of use and very speedy downloading (less than $20 \mathrm{~s}$ ) of the home page and the other web pages. All information should be accessible with a maximum of three mouse clicks.
- The site content would be continuously updated.

- The site would be bilingual (Greek and English).

- In order to increase the customer retention the site would offer to frequent users the option of getting access to a second layer of specialised and high-quality information provided by the analysts of the company by becoming members of the ABC Club*. Membership to the club would provide users with a number of attractive privileges. Next to the retention element of this strategy, direct promotional activities regarding future products would be possible using the club database.

- A second instrument of customer retention would be an educational section providing a frequently updated educational content partly based on actual customer questions and interests.

\subsubsection{Synergy (organisational aspects)}

(a) Front Office. The Web site became a clearly visible part of the promotional and PR campaign prior to the launching of the fund and one of the basic elements of the official presentation to the public. The site address was also visible to all documents and communication material of the company. An extended direct mail campaign would support the site introduction.

(b) Back Office. A team of analysts would be responsible for the updating the site content, daily market comments and analyses while a marketing team would handle the contacts with the users, and would be responsible for the management of the $\mathrm{ABC}$ Club database and the online commercial activities.

(c) Third parties. An extensive effort was made for registering the site URL with the major search engines, meta-search engines and Web directories. Also advertising banners were placed in a number of high traffic web sites.

\subsubsection{System (technical and technological as- pects)}

Important element of the site design was the browser independency and simplicity. It was decided that for reasons of efficiency the company should host the site itself. Important aspects to be addressed 
were the content management, the continuous technical improvement and the management of the incoming user information and inquiries. The security requirements were moderate at the initial stage with the only protected area being the $\mathrm{ABC}$ Club* section. Also special attention was placed in monitoring of the site performance.

\subsection{Creative process and evaluation}

Based on these guidelines a detailed site map was drafted indicating the main elements as well as the details of the site content. In the initial form the site was extremely simple to use as well as fast, something that was obviously very much appreciated by the user. The first major renovation of the site was done after a year.

The combination of advertisement and PR as the main promotional instruments in combination with an original positioning proved to be fairly successful and the site received a lot of free publicity prior to the launching. The most important elements of the evaluations that took place after the site launching and later on were:

- The 4S framework covers all major strategic and operational areas of the Web operation of ABC Portfolio*.

- The Strategic and Marketing plan based on the $4 \mathrm{~S}$ framework allowed the site designers to concentrate on the technical aspects of building the site, saving them from a lot of time in planning and research work. The construction time was very short.

- The synergetic effect of the promotional campaigns and the PR activities attracted within 3 weeks an average of around the 16000 hits per day. This number was at that time the highest for a Greek commercial site (excluding the sites of Internet Service Providers).

- The ABC Club* became highly popular in a short time; the number of the registered users after a year reached the 35000 persons.

- The number of the daily hits after a year was close to the number of the registered $A B C$ Club* users, indicating a high degree of customer retention.

- The group of users registered in the ABC Club* became a very valuable target group for future ABC Portfolio*.

*ABC Portfolio, ABC Mutual Fund and ABC Club are aliases.

\subsection{Case 2: the Fidelity Insurances** case}

The Fidelity Insurances** is a mid-sized Greek insurance organization with a good market position and reputation. The time the Fidelity Insurances** decided to enter the E-Commerce arena coincided with some difficulties the company experienced in marketing a line of innovative products (special types of insurances, services and credit cards, etc.), some of them unique to the Greek market. The existing distribution channel (agents) was showing low interest for these new products, that like most innovations in the services sector, required a lot of push effort and personal selling.

The Web project was the first serious Internet operation of the company. The whole project was based on a strategic and operational blueprint drafted according to the 4S Web-Marketing Mix methodology and took place in the end of 1998. The 4Ss in detail:

\subsubsection{Scope (strategy)}

(a) The prime strategic goal was to increase the market awareness and if possible the sales of the before-mentioned new services by communicating directly with the market, outside the traditional distribution channels. Furthermore it was important for Fidelity Insurances $* *$ to take a lead in the E-Commerce for assurance products in Greece. This, next to the obvious positive effect on the bottom line, would also enhance the company's image as a modern, reliable, innovative, customer friendly and efficient organization.

Improving the customer retention through better communication, customer management and customer service as well as being prepared for global competition were also strategic objectives of the E-Commerce project, in line with the long-term organizational vision.

Another important strategic goal was the creation of a customer and prospects database based on customer data collected online. The database would 
provide the agent network with sales leads, this way reducing the chances of channel conflict and ensuring the support of the network to the online project. This database would be used also for direct marketing and other types of traditional promotional activities.

(b) The competitive analysis indicated that all major insurance players in Greece had already an online presence. A closer look however revealed that the Web sites of the vast majority of competitors were much less professional than one would expect. A common element of almost all sites was a brochure-like presentation with massive texts, very slow downloading times, limited interaction and no online transaction possibilities. The effort of most companies was obviously to impress the online visitors by presenting them with a bulk of information about the organisation, its services and financial achievements, in fact doing nothing more than providing the type of information that most web users would find annoying or irrelevant. The product information was often based on long texts, sometimes containing even the contract fine print.

(c) Research on the Internet users' demographics was combined with the company information as to customer profiles in order to identify market segments and potential target groups. The study identified a number of prospective target groups for the online products among Fidelity's customer population and non-customer segments. The market potential was estimated to be the $4 \%$ of the Greek households at that time.

(d) The strategic function of the Web presence was defined by a combination of Transactional, Promotional and Informational roles, with the management placing more emphasis on the first one of them. The study revealed though, that the expectations as to online sales should be very limited, given the stage of development of E-Commerce at that time in Greece. This warning was indeed confirmed by the subsequent experience.

The strategy as described above would be reviewed in regular intervals considering the fast changing market conditions and technological developments.

\subsubsection{Site (operational aspects/web experience)}

Based on the above strategic issues the operational elements of the study were focused on identifying a number of elements likely to play a major role in the site design. These elements were:

- the online customer profiles and their needs;

- the customer's motives to search for and purchase insurance products;

- the way potential site visitors are likely to search the Internet for the site products and browse the information in it;

- the physical versus the virtual interaction process and the emotional issues likely to affect the customer experience.

Based on these aspects the following suggestions were drafted:

(a) 'Security', 'Advice' and 'Reliability' were the generic concepts that would communicate the site's emotional positioning. These attributes were also in line with the 'physical' company image.

(b) The Web presentation would be differentiated from the competition by means of user friendliness, focus on the site visitor's needs, value, and efficient service.

(c) Important elements of the Web Experience were the content, the interactivity and the service offered online. Information about the company, its network and financials was also available but only as a background options.

(d) Since assurance products are typically requiring personal selling one of the site objectives was to simulate as much as possible the conditions of the physical interaction between the sales rep and the customer and to guide the online customer through an interactive process that would lead to the successful conclusion of an online sale.

(e) Considering the technical limitations of that time, it was evident that multimedia was a future option and in the initial stage the online presentation was to be based on more conventional web tools. Important elements of the presentation were:

- Ease of navigation. Necessary condition was that all available information could be accessible to the site visitor with a maximum of three mouse clicks. A simple and very easy to use start menu would save time eliminating 
unnecessary searching while the maximum page download time should not exceed the 20 $\mathrm{s}$ for an average user.

- Easy access to information about the products and services. The product information was to be presented in three layers starting from a short description of the product, followed by a summary of the main product attributes and in the third layer offering an extended product description for potential customers interested in details. Potential visitors could identify this way very early in the search process whether a specific product or service was interesting and minimize this way the searching time.

- In all information layers the customer had access to a calculation tool and an order/ information request form. The customer was also presented the option to be contacted by a sales rep and ask for online assistance in filling in the order form.

- Easy ordering procedures and special incentives (discount) for new customers ordering products online were aiming at lowering the threshold of engaging in online transactions.

(f) An important issue was the selection of a domain name. Since the original Greek brand name translated in English was yielding a difficult to remember and write word, a new domain name was found.

\subsubsection{Synergy (organizational aspects)}

(a) Front Office integration. A detailed introduction plan was drafted combining traditional media (Direct Mail, advertisement, PR) and electronic media (online advertisement, multimedia presentation) for supporting the site during the commercialisation and the initial stage of its online presence. The campaign was to be fully compatible with the existing and future marketing activities. The message of the campaign should be focused on value and advantages of doing business online that would be attractive for the target groups. The online activity should be also integrated as much as possible to every future traditional promotional action in order to increase the market awareness as to company's online presence.

(b) Back office integration. The internal processes and resources had to be reviewed in order to spot the possible areas of conflict and the weak points of the existing organisation (partly) migrating to an online-based environment. The review identified the main organizational issues to be addressed and produced a number of suggestions facilitating the smooth integration of the web activity into the existing business. Important topics addressed were the communication process, the integration of E-Commerce within the infrastructure legacy, the site administration, order fulfilment and the content management. Other essential issues were the problems of the online customer service and the efficient as well as fast handling of transactions, customer problems and e-mails. Such issues indicated the need for forming a separate E-Commerce organizational unit. Finally special attention was placed on the management of the databank and the site traffic data.

(c) Third parties. The site was registered with all major web directories and search engines while special attention was placed on increasing the findability of the site by the, in that time, growing number of meta-search engines. During the introduction stage some online advertisement activities aiming at the greater possible exposure of the brand would also take place.

\subsection{System (technical and technological aspects)}

The main technological parameters of the project were not much different than the previous case, with a few new dimensions, namely the settlement of the online transactions and the increased security requirements.

Other important issues were the hosting of the system, that the company kept in-house rather than outsourcing it, the technical support of the E-Commerce applications and the criteria for selecting the designer and constructor of the site.

\subsection{Evaluation of the Fidelity Insurance ${ }^{* *}$ project}

Fidelity Insurances** became the first Greek and one of the pioneering sites in Europe to offer insurance services for sale on the Internet. Like the previous case, one of the main advantages of the $4 \mathrm{~S}$ methodology was the important time saving in site- 
building time and the realization of an innovative and clearly positioned online presentation. The site attracted a lot of attention in Greece and became an example for other insurance sites.

Although no financial or traffic data have been released the management considered that the site had achieved most of its strategic objectives, becoming a valuable marketing tool and maintaining its original, initial form for almost 3 years. The long life cycle of the site could be attributed to the fact that the comprehensive strategic and operational analysis as the foundation of designing the Fidelity Insurance** site, gave to the site a long-term competitive advantage, saving substantial amounts by preventing frequent changes and experimentation.

**Fidelity Insurance is an alias

\section{Summary}

The paper reviews the criticism on the role of the Marketing Mix 4Ps model as the paradigm of the traditional marketing and evaluates its role in ECommerce defined markets. The frequent criticism of the 4P Marketing Mix model as the backbone of the traditional, physical marketing management is also applicable to online marketing management, while two more factors further undermine the effectiveness of the model as the marketing management platform in virtual environments:

- The very role of the 4Ps in an online environment is quite different than their role in a physical market setting. The 4Ps are not the critical factors of the virtual marketing process but rather elements of the total Web Experience. In this respect the effect of these factors on the consumer's decision making process is much more limited in the virtual environment than in the physical one.

- The 4Ps are operational parameters. Management of E-Commerce activities based only on the $4 \mathrm{P}$ framework ignores the dynamic strategic elements of the online marketing process that are extremely important for survival in the volatile and fast-changing virtual markets.

As an alternative option the paper proposes the $4 \mathrm{~S}$
Web-Marketing Mix framework that allows the web marketer to solve the strategic and operational issues of the Internet marketing in an integral and efficient way. The proposed framework emphasises the need for a new approach towards the online marketing, by fully integrating the virtual activities within the existing company strategy, marketing and operations. The practical objective of the paper is to help established or future E-Businesses to utilise the Internet technology and the online market potential in an efficient way, adding value to the overall company operations. The methodology proposed is, however, the subject of further research and empirical testing.

The review of two field projects outlines some interesting aspects. The companies in question have experienced both projects as successful and both projects have been also seen as very innovative in the Greek Internet Market. Yet the purpose of presenting these cases is not to evaluate their commercial merits (measuring the ROI of online activities is a notoriously complicated issue) but rather to explain how the Web-Marketing Mix methodology can be applied in practice.

Summarizing the cases we can identify the following main conclusions:

- The 4S framework defines the main elements of an E-Commerce project in a simple and practical way. It offers a platform for drafting a comprehensive Strategic and Marketing plan for the fast changing Web environment.

- E-Commerce plans drafted on the basis of the 4S methodology save considerable time in designing and completing the online project. Presenting web designers with a strategic and operational blueprint allows them to focus on the implementation aspects of the project

- A deep and extensive situation analysis and the consequent identification of the $4 \mathrm{~S}$ factors is likely to yield a Web site that can maintain for longer time its proprietary competitive advantages, reducing the cost of upgrades and updates.

- Planning and implementing an E-Commerce B2C project involves a considerable amount of classic marketing effort. The Scope, Site and to a lesser extend the Synergy elements of the mix 
require clear strategic vision and market orientation.

- The Web site's competitive advantage must be based on its market orientation and the customer's Web Experience rather than technology. E-Commerce must therefore be considered and approached primarily as a marketing management problem rather than a technological issue.

\section{Acknowledgements}

The earlier version of this paper was presented at the HICSS-35 Conference, Big Island, Hawaii, on January 2002.

\section{References}

[1] http://www.etforecasts.com/pr/pr201.htm

[2] http://www.emarketer.com/ereports/ecommerce_b2c/

[3] http://ecommerce.internet.com/opinions/article/ 0,1467,3551_751371,00.html

[4] http://news.ft.com/ft/gx.cgi/ftc?pagename $=$ View\&c $=$ Article \&cid $=$ FT3JIJ9RCLC\&live $=$ true $\&$ tagid $=$ ZZZC00L1B0C\& Collid $=$ ZZZ96PECC0C

[5] http://www.webmergers.com/editorial/article.php?id $=10$ C. Allen, D. Kania, B. Yaeckel, Internet World Guide to One-To-One Web Marketing (Internet World Series) 1998, Mecklermedia.

[6] The Boston Consulting Group Inc, 2000. Winning in the New Economy: Consumer Marketers Face the Challenges http://www.bcg.com/publications/files/ChapterTwo_Feb_01.pdf

[7] C.M. Christensen, 2000, After the Gold Rush: Patterns of Success and Failure on the Internet. www.innosight.com

[8] C.M. Christensen, in: The Innovator's Dilemma, Harvard Business School Press, Cambridge, MA, 1998.

[9] M.E. Porter, Strategy and the Internet, Harvard Business Review, March 2001, pp. 63-78.

[10] N.H. Borden, The concept of the Marketing Mix, Journal of Advertising Research 4 (1964) 2-7.

[11] X. McCarthy, in: Basic Marketing, a Managerial Approach, Irwin, Homewood, IL, 1964.

[12] C. Grönroos, in: From Marketing Mix to Relationship Marketing-Towards a Paradigm Shift in Marketing, Management Decision 34/5, MCB University Press, Bradford, UK, 1997, pp. 322-339.

[13] R.E. Goldsmith, The personalised marketplace: beyond the 4Ps, Marketing Intelligence and Planning 17 (4) (1999) 178-185.
[14] M. Rafiq, P.K. Ahmed, Using the 7Ps as a generic marketing mix, an exploratory survey of UK and European marketing academics, Marketing Intelligence and Planning 13 (9) (1995) (MCB University Press).

[15] K. Ohmae, in: The Mind of the Strategist: The Art of Japanese Business, McGraw-Hill, New York, 1982.

[16] A.R. Bennet, The five Vs-a buyer's perspective of the marketing mix, Marketing Intelligence and Planning 15 (3) (1997) 151-156.

[17] B. Lauterborn, New marketing litany: four Ps passé: C-words take over, Advertising Age 61 (41) (1990) 26.

[18] S. Godin, The New P's of Marketing, sales and Marketing Management, Bill Communications, New York, February 2001.

[19] D. Hoffman, T. Novak, A New Marketing Paradigm for Electronic Commerce. The Information Society, Special issue for electronic Commerce 13 (January-March 1997) 43-54.

[20] J. Sterne, in: World Wide Web Marketing: Integrating the Web into Your Marketing Strategy, 2nd Edition, Wiley, New York, 1999.

[21] K. Bayne, in: The Internet Marketing Plan, Wiley, New York, 1997.

[22] T. Vassos, in: Strategic Internet Marketing, Que, Indianapolis, IN, 1996.

[23] http://www.ecademy.com

[24] http://www.pwcglobal.com/

[25] http://www.i-strategies.com/homepage.html

[26] http://www.jaderiver.com/

[27] D. Chaffey, R. Mayer, K. Johnston, F. Ellis-Chadwick, in: Internet Marketing, Strategy, Implementation and Practice, FT/Prentice Hall, Englewood Cliffs, NJ, 2000.

[28] P. Seybold, in: Customers.com, Century Business Books/ Random House, London, 1999.

[29] R.W. Oliver, The Seven Laws of E-Commerce Strategy, Journal of Business Strategy 29 (10) (2000) 8-10.

[30] R. Amit, C. Zott, Strategies for Value Creation in E-Commerce: Best Practice in Europe, European Management Journal 18 (5) (2000) 463.

[31] B. Mahadevan, Business models for internet based E-Commerce an anatomy, California Management Review 42 (2000) 4.

[32] M. Rappa, Business models on the web, 2001 http:// digitalenterprise.org/models/models.html

[33] C. Hart, N. Doherty, F. Ellis-Chadwick, Retailer adoption of the Internet-Implications for retail marketing, The European Journal of Marketing 34 (8) (2000) 954.

[34] A.A. Angehrn, Designing mature Internet strategies: The ICDT Model, European Management Journal 15 (4) (1997) 361.

[35] E.K.R.E. Huizingh, 1999. Towards successful electronic Commerce strategies: An hierarchy of three management models, University of Groningen (NL). http://www. ub.rug.nl/eldoc/som/b/99B45/

[36] E. Lawrence, B. Corbitt, J.A. Fisher, J. Lawrence, A. Tidwell, in: Internet Commerce, 2nd Edition, Wiley, Australia, 1999. 
[37] P. Bickerton, M. Bickerton, U. Pardesi, in: CyberMarketing, Chartered Institute of Marketing Series, ButtenworthHeineman, Oxford, 1996.

[38] T. Patty, 1997. Mastering the Five P's of Marketing. www.chiatday.com/raw_materials/insights $/ 5 \mathrm{ps} / 5 \mathrm{p}_{-} \mathrm{mkt} . \mathrm{html}$

[39] J. O'Connor, E. Galvin, in: Marketing and Information Technology-The Strategy, Application and Implementation of IT in Marketing, Pitman, London, 1997.

[40] D. Hoffman, T. Novak, A. Schlosser, 2000, Consumer Control in Online Environments, Working Paper, eLab, Owen Graduate School of Management, Vanderbilt University.

[41] P. Kotler, in: Marketing Management, 2000. The Millennium Edition, Prentice-Hall, Englewood Cliffs, NJ, 2000.

[42] Watchfire Whitepaper Series, 2000. Bad Things Shouldn't Happen to Good Web sites, Best Practices for Managing the Web Experience.

[43] Porter, M.E., 1980, Competitive Strategy, Techniques for Analyzing Industries and Competitors, The Free Press.

[44] A. Harberberg, A. Rieple, in: The Strategic Management of Organisations, Prentice-Hall, Englewood Cliffs, NJ, 2001.

[45] Forrester Research, May 2000, Targeting European Consumers-Market Overview, Edwin van der Harst, www. forrester.com

[46] C. Shapiro, R. Varian, in: Information Rules: A Strategic Guide to the Network Economy, Harvard Business School Press, Boston, MA, 1999.

[47] M.E. Porter, in: Competitive Advantage, Free Press/Macmillan, New York, 1985.
[48] HICSS-35, Proceedings of the Hawaii International Conference in Systems Sciences, 2002, Big Island Hawaii.

\section{Additional literature}

R. Amit, C. Zott, Strategies for value creation in E-Commerce: Best practice in Europe, European Management Journal 18 (2000).

L. Bielski, E-Business models stress putting the customer first, ABA Banking Journal, July 2000.

R. Kalokota, A.B. Whinston, Electronic Commerce. A Manager's Guide. Addison-Wesley, Reading, MA, 1997.

D. Kosiur, Understanding Electronic Commerce, Microsoft Press, USA, 1997.

Y. Malhotra, 1997. Internet Enterprise Strategy and Design: A Real-World Introduction to Electronic Commerce-An Online Guide for Net Entrepreneurs and Managerial End Users.http:/ /www.brint.com/enterprise.htm

A. Ranchhod, F. Zhou, J. Tomson, Factors Influencing Marketing Effectiveness on the Web, Information Resources Management Journal (2000) 4-12.

T. Robinson, Modelling for Success: Why Strategy Comes First, Arthur Andersen Consulting, 2000.

L. Tompson, E-Commerce: Changing the rules of strategy implementation. Strategy and Leadership (2000) 35-39. 